\title{
Milk sharing: boon or biohazard?
}

$\mathrm{M}$ ore than two decades after fears of HIV transmission forced the closure of all but one of Canada's 23 milk banks, regulators, medical professionals and mothers remain divided on the safety of sharing breast milk.

Increased public pressure, regulatory oversight and evidence of the efficacy of modern screening and pasteurization processes are speeding efforts across the country to reopen milk banks to serve hospitalized babies - paradoxically at the same time health officials are warning mothers against the dangers of informally sharing their breast milk.

Confounding the debate is the Januslike nature of the milk itself. Today, breast milk's nutritional merits as a food are difficult to separate from its "ick" factor as a body fluid capable of transmitting disease, says Dr. Sharon Unger, a neonatologist at Mount Sinai Hospital in Toronto, Ontario, and professor of pediatrics at the University of Toronto.

Up until the AIDS crisis hit Canada in the 1980s, human breast milk was more valued for its antibiotic properties than feared for its infectious potential, says Maureen Fjeld, a Calgary-based lactation consultant who witnessed the rise and fall of Alberta's milk banks.

While health officials offered many justifications for the closures - among them, that women had access to electric breast pumps and therefore didn't need the banks - "the reality was they were scared of infecting someone as the blood banks had done," says Fjeld.

The BC Women's Milk Bank in Vancouver, British Columbia, was the sole survivor of the closures, and today carefully rations its supply to only the most vulnerable hospitalized babies. Sunnybrook Hospital in Toronto, Ontario, ships donor milk from the United States to feed its sick and premature babies. Other hospitals and mothers have no choice but to rely on formula when natural sources of breast milk run dry.

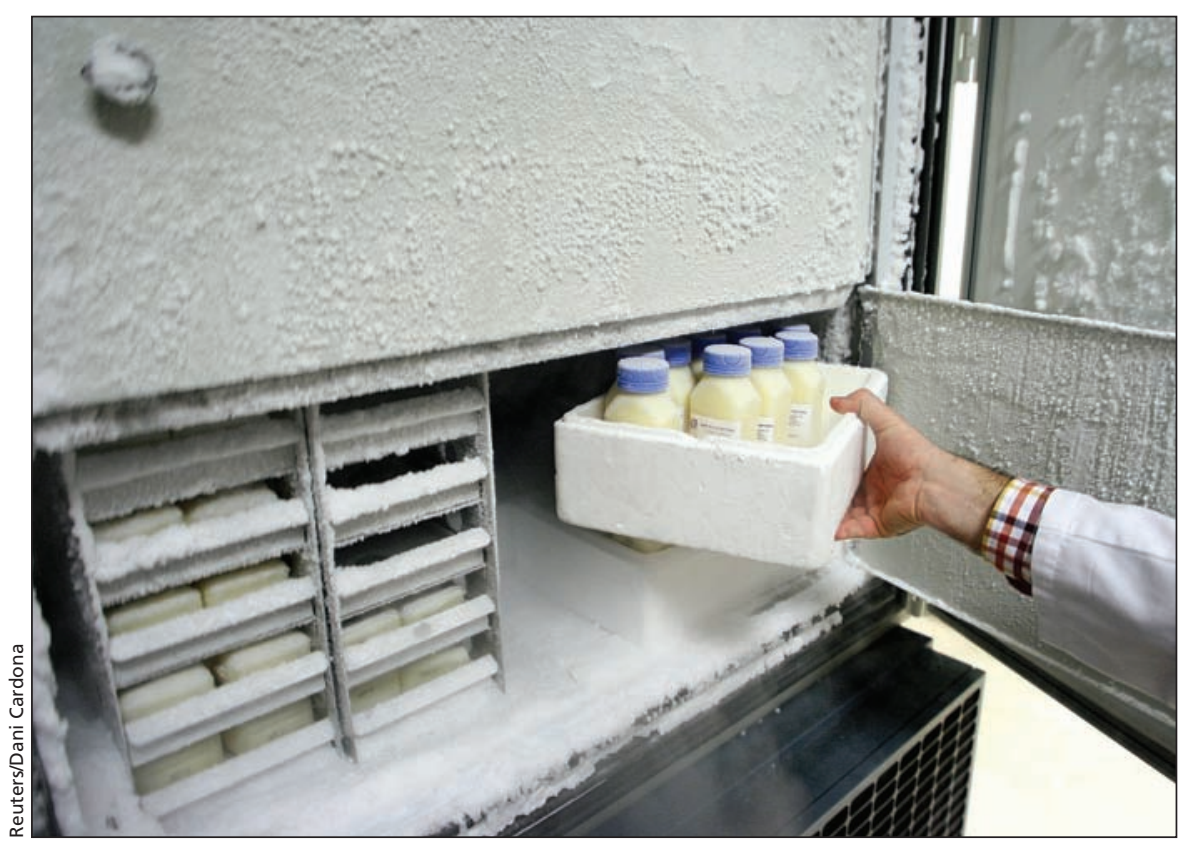

Frozen breast milk is stored at a bank in Palma de Mallorca, Spain.

That narrow menu may soon expand for the neediest babies. Sunnybrook Hospital, Mount Sinai Hospital and the Hospital for Sick Children are in the process of establishing a shared milk bank in Toronto. Héma-Québec, the nonprofit organization that manages Quebec's blood supply, is researching the risks and benefits of reopening a milk bank in that province.

Stringent guidelines for donor screening and pasteurization adopted from blood services and the dairy industry, along with regulatory oversight from Health Canada and the Canadian Food Inspection Agency, have removed any health risk milk banks may have posed in the past, says Unger.

Toronto's new bank, like Vancouver's, will abide by industry standards for the establishment and operation of milk banks set by the Human Milk Banking Association of North America.

"Association banks dispense more than one and a half billion ounces of human milk every year and they've never had a case of disease transmission," says Unger. "All our ducks are in a line, as far as safety goes. The next thing I think governments are looking for is the long-term health outcomes and cost savings of reopening the banks."

Because formula companies provide their products to hospitals for free, public funding for milk banks requires proof that there are health benefits and costs efficiencies to be achieved from using donor milk, says Unger.

To that end, the Canadian Institutes of Health Research have funded a team of Toronto neonatal experts to conduct a five-year study of the health and financial impacts of donor milk compared to preterm infant formula as a substitute for mother's own milk for very low birth weight infants. Initial findings are expected within two years, says Unger.

That's too long for mothers who are worried about health risks associated with recent recalls of infant formula. Many now turn to their peers for milk when their own supplies run low - a practice regulators and health professionals such as Unger call "dangerous."

Informal breast milk exchanges have exploded online, linking women from around the world. One such group, 
called Eats on Feets, has become the world's largest human milk sharing network, with some 87 regional chapters in 18 countries. Each chapter connects hundreds of mothers through the social networking site Facebook.

Led by Montréal, Quebec-based mother and breastfeeding advocate Emma Kwasnica, it claims to serve women that milk banks "won't touch" because their babies are too healthy.

"Whether it's for cultural reasons and they just don't understand how to breastfeed, because so few of us do anymore, or it's a physical condition or stress that's preventing them from bringing in a full supply, these women have no other option," Kwasnica says. "At first, people are grossed out, but turning to other women is not so hard to understand. After all, we've been wet nursing since the beginning of time."

While Eats on Feets matches women locally and the exchanges are free, the demand for breast milk is so great that a black market has mushroomed on websites such as Craigslist and Ebay, with women hawking their excess milk at several dollars an ounce to far-flung and desperate mothers.

The potential to thus expose children to viruses, bacteria and traces of prescription and nonprescription drugs has prompted Health Canada and the United States Food and Drug Administration to release warnings against both voluntary and paid exchanges (www.hc -sc.gc.ca/ahc-asc/media/advisories-avis /_2010/2010_202-eng.php and www.fda .gov/ScienceResearch/SpecialTopics /PediatricTherapeuticsResearch/ucm 235203.htm).

Kwasnica agrees that purchasing milk from an unknown mother is risky but argues that the risk is mitigated when mothers are able to meet in person and provide testing results. "New moms have just gone through the most intensive screening of their lives. They know if they're positive for HIV or hepatitis or syphilis or gonorrhea, and they can provide ready proof of that information. Not only are women asking to see blood screening records, they're seeing the healthy baby gurgling away on the other mom's hip. If a mother's milk is good enough for one healthy, chubby child, how come it's labelled a biohazard for another?"

Many European milk banks rely on just such donor screening to ensure the safety of their supply, rather than compromise its nutritional quality through pasteurization, says Fjeld.

Eats on Feets provides its members with information on "flash pasteurization" methods that can easily be performed at home. "All you need to do is put a glass jar with $150 \mathrm{ml}$ of feed in a pot of water, bring that water to a quick boil, take the jar out and let it cool," says Emma. "They're doing it over hot coals in Africa and it's been proven to eliminate bacteria and viruses, including HIV, without compromising the quality of the milk."

But unless pasteurized milk is tested for heat-resistant bacteria, mothers are gambling with their children's health, says Unger. "Even milk banks will get some culture positive milk after pasteurization. The difference is the milk banks can test for that and chuck it out."

Milk banks also test other pathogens, Unger adds. "There's something in the mother-baby unit that protects babies from certain bacteria in their own mother's milk, but with a stranger's milk you just don't know."

Some mothers may not know they've picked up an infection postscreening, she says. "What if a woman has a cold sore or herpes lesion on her breast? She may not be aware of it, but such a virus can be fatal to newborns. Why would you take that risk?"

Kwasnica counters that formula feeding may be just as risky, if not more so. "These babies are getting constipated and sick. They're pooing out blood and not gaining weight. We know formula rips up the insides of their intestines and opens their guts up to pathogens. We know it's been linked to diabetes, respiratory illness, gastrointestinal illness and heart disease, to name a few. We've got to talk about relative risk, and not consider it lightly, before freaking out about sharing breast milk."

Health Canada has already weighed the relative risk, says Unger. "Sharing unprocessed breast milk is dangerous. There's a reason infant mortality has dropped, and a lot of it has to do with current public health practices. I have faith in those practices, and for all formula may not be as good as mother's own milk, it is safe."

Women should have the chance to weigh the evidence, says Teresa Pitman, a breastfeeding advocate for $\mathrm{La}$ Leche League Canada. "Put out a warning, but why not also provide guidelines for safe milk sharing for the women who are going to do it anyway, just like Health Canada used to do for [raw] cow's milk?"

La Leche League doesn't encourage milk sharing, but recommends women consult health professionals to ensure proper testing is conducted prior to any exchange.

Kwasnica, though, believes that no amount of caution or regulation will ever eliminate the sharing of milk. "No one will ever be able to regulate what women do with their bodies and their milk. There are mothers of premature babies who secretly bring their friends' milk into the hospital and say it's their own. It's sad these women have to lie, but they're taking choice back into their own hands." - Lauren Vogel, CMAJ

CMAJ 2011. DOI:10.1503/cmaj.109-3767 